\title{
Chc lesterase Activities in the Gustatory Region of the Rat Tongue and Their Inhibition by Bitter-tasting Substances
}

\author{
Seishi Tsuchiya \\ Pharmaceutical Institute (Prof. S. Okui), \\ Tohoku University School of Medicine, Sendai \\ Tsuyoshi Aoki \\ Department of Physiology (Prof. M. Wada), \\ Tohoku University School of Medicine, Sendai
}

The localization of cholinesterase activity in the tongue of albino rats was histochemically demonstrated by the thiocholine technique of Koelle and Friedenwald, modified by Gomori. The taste nerve fibers innervating the taste buds in the vallate and fungiform papillae contained cholinesterase of both true and pseudo types, the former being predominant. The taste buds themselves failed to show definite cholinesterase activity. True and pseudo cholinesterases were also found in the different sensory nerve endings in the lingual papillae, in the subepithelial nerve plexus, in the motor end plates of the lingual muscle, and in the autonomic nerve fibers innervating the serous Ebner's gland, mucous Weber's gland and the arterioles.

The cholinesterase activity in the taste bud areas was found to be inhibited by several kinds of bitter-tasting substances, including quinine hydrochloride, methantheline bromide, berberine hydrochloride, s-methylephedrine hydrochloride, phenobarbital sodium and sodium dehydrocholate. Among the bitter substances tested, only phenylthiocarbamide, a substance with dual taste reaction, failed to inhibit the cholinesterase. Sweet-tasting substances such as sucrose, sodium cyclohexylsulfamate and saccharin sodium were all ineffective in inhibiting cholinesterase. It was suggested that the inhibition of cholinesterase activity in the vicinity of taste buds may be associated with the mechanism of bitter taste.

Baradi and Bourne $e^{1-3}$ found histochemically that several kinds of enzymes such as alkaline phosphatase, acid phosphatase, simple esterase and lipase were distributed in the gustatory region of the rabbit tongue, each of which showing different localization, and that various substances with pronounced taste inhibited or accentuated the activity of some of these enzymes in different sites. Based on these findings they advanced a hypothesis that the chemical process which is associated with the differential inhibition or acceleration of enzymes in the vicinity of taste buds might be responsible for the mechanism of inducing

Received for publication, October 12, 1966. 
taste sensation, and also for the mechanism of discriminating between a variety of tastes. ${ }^{1-3}$

Recently one of the authors ( $\mathrm{T}$ ) found in an in vitro experiment that the activity of cholinesterase contained in the rabbit serum is definitely inhibited by some of the bitter-tasting substances (unpublished data). On the other hand, recent histochemical studies have shown that in the tongue of the rabbit ${ }^{4,5}$ and some primates ${ }^{5}$ as well as of man $^{6,7}$ the cholinesterase is abundantly localized in the gustatory epithelium especially being associated with the taste buds.

The present work was undertaken to examine histochemically whether the bitter substances affect the cholinesterase actually present in the gustatory region of the tongue. The rat was chosen as the test animal for the present experiment, since this animal is reported to have a taste sensibility similar to that of human being. ${ }^{8-12}$

So far little information is available concerning the cholinesterase localizations in the rat tongue. Accordingly the present communication includes a preliminary observation on the distribution of cholinesterase activity in the tongue, especially in the gustatory region of this animal. The localizations of this enzyme in the rat tongue were found to be essentially similar to, but different in some respects from those hitherto reported in other mammals ${ }^{4,5}$ as well as in $\operatorname{man} .{ }^{6,7}$

\section{Materials and Methods}

A hundred and fifteen mature female albino rats, weighing 170 to $200 \mathrm{~g}$, were used for the present study. The whole tongue was removed immediately after the animal was killed by stunning blow and decapitation. Round slices in appropriate thickness were cut from the different part of the tongue, and they were fixed in chilled $10 \%$ neutral formol saline for various length of time, ranging from 15 minutes to 4 hours. In some cases unfixed materials were also used. The cross sections were cut on the freezing microtome at 20 to $30 \mu$ routinely, but some sections at 40 to $50 \mu$.

The localization of cholinesterase activity was demonstrated by Gomori's modification $^{13}$ of the thiocholine technique of Koelle and Friedenwald.14,15 As the substrate for the enzyme, acetylthiocholine iodide (Sigma) and butyrylthiocholine iodide (Sigma and Hoffman-La Roche) were used. The incubation was carried out at $37^{\circ} \mathrm{C}$ in the substrate solution at $\mathrm{pH}$ of approximately 5.8-6.0 for a period of time ranging from 1 to 6 hours, routinely for about 2 hours. After the incubation, the sections were rinsed in three or four changes of saturated sodium sulfate solution. They were then placed in a dilute solution of yellow ammonium sulfide for about 4 minutes, rinsed in distilled water, and left in $10 \%$ neutral formol saline for about 20 minutes. These sections were flattened on clean glass slides coated with albumen glycerol, and after being allowed to dry overnight they were dehydrated and mounted with Canada balsam. 
As the cholinesterase inhibitors, physostigmine (eserine) salicylate (Merck), diisopropylfluorophosphate (DFP, Merck) and tetraisopropylpyrophosphoramide (iso-OMPA, Light) were used. Further details on the procedures will be given throughout the text.

\section{RESULTS}

\section{Reactive Sites in the Papillary Area}

The dorsal surface of the rat tongue is covered with papillae of three different types: filiform (or conical), fungiform and vallate papillae.16,17 Filiform or conical papillae, which are widely distributed throughout the most part of the tongue dorsal surface, have no taste buds. Fungiform papillae are seen to be scattered sparsely over the anterior two-thirds of the tongue dorsum, and each of them carries only one small taste bud at the center of the top surface ${ }^{18}$,19 (Fig. 3). A single vallate papilla, which occurs in the middle of the extreme base of the tongue, bears many taste buds of relatively large size along the wall of the gutter, usually below the level of about two-thirds of the trench surrounding the papilla (Fig. 1).

Reactions with acetylthiocholine iodide. Among the lingual papillae, the most prominent staining reaction was found in the area of the vallate papilla. As shown in Fig. 1, the sections incubated with acetylthiocholine revealed strongly reactive dense nerve network in the subepithelial connective tissue along the gutter wall, giving the appearance of a U-shape cup holding the gutter. The upper limit of the cup was confined approximately to the level of first taste buds, indicating that this nerve plexus is closely associated with the taste buds.

The taste buds themselves showed almost no evidence of enzymatic activity in contrast to the strong reaction in the nerve fibers underlying them (Figs. 1, 2). However, thick sections, especially obtained from unfixed materials, often gave some staining in the basal portion of the taste buds without showing any specific sites of intragemmal localization. Intergemmal as well as perigemmal nerve fibers which were demonstrated in the rabbit foliate papillae $e^{4,5}$ were not found in the rat vallate papilla.

From the base of the papilla vallata, fairly thick nerve tracts accompanied with some ganglion cells, both strongly reactive with acetylthiocholine, enter the papilla, forming a coarse network in the connective tissue of the papillary core (Fig. 1). Some of the thin nerves derived from these nerve bundles were seen to extend up and reach the underneath of the epithelial layer lining the top of the papilla.

In most part of the tongue dorsum, a delicate nerve network reactive with acetylthiocholine runs along the connective tissue layer just beneath the filiform papillae, and it gives off fine nerves into the core of every filiform papilla, and also into the fungiform papillae which sparsely intervene between the filiform papillae. 
Most of the nerve fibers entering the core of filiform papillae end freely immediately underneath the papillary epithelium (Fig. 4), and those in the fungiform papillae terminate surrounding the base of the taste bud at the top of the papillae (Fig. 3). The taste buds in the fungiform papillae were also found to be devoid of definite staining reaction with acetylthiocholine (Fig. 3). Some of the filiform papillae contained nerve endings of encapsulated type, which gave intense reaction with acetylthiocholine. They are probably either Meissner's corpuscles or Krause's end bulbs.

Reactions with butyrylthiocholine iodide. The distribution of the enzymatic reaction with butyrylthiocholine in the papillary area was almost comparable to that obtained with acetylthiocholine, though the staining reaction was generally far less intense. Only one exception was found in the sensory nerve endings of encapsulated type in the filiform papillae. They always gave reaction with butyrylthiocholine as strong as with acetylthiocholine, but the nerve fibers directly connected with them showed no reactions with both substrates.

\section{Reactive Sites in the Rest of the Tongue Tissues}

Enzymatic reactions with thiocholine substrates were noticed in the various structures in the tongue, most of them being associated with the nervous elements. The main sites of the localizations will be briefly described. In all of them the incubation with acetylthiocholine gave stronger reaction than with butyrylthiocholine.

1) The motor end plates in the lingual muscles showed most prominent staining reaction, the muscle fibers themselves giving negative reaction (Fig. 5).

2) Various tissues in the tongue, particularly the lingual muscles, are richly vascularized, and all of the arterioles were seen to be richly invested with numerous nerve fibers reactive with both substrates (Fig. 6).

3) The glandular acini of both Ebner's (serous) and Weber's (mucous) glands were surrounded with reaction-positive nerve fibers (Fig. 7). Similar innervations were also found around the duct of Ebner's gland, but not around that of Weber's gland.

\section{Effects of Cholinesterase Inhibitors}

In this series of tests, attention was largely focused to the papillary area, particularly to the vicinity of the taste buds in the vallate and fungiform papillae.

Effect of eserine. The sections were incubated with the substrate solutions, to which eserine was previously added in graded concentrations ranging from $10^{-4}$ to $10^{-7} \mathrm{M}$ just before the experiment, and these were compared with the control sections from the same specimen similarly incubated with the substrate solution without eserine. 


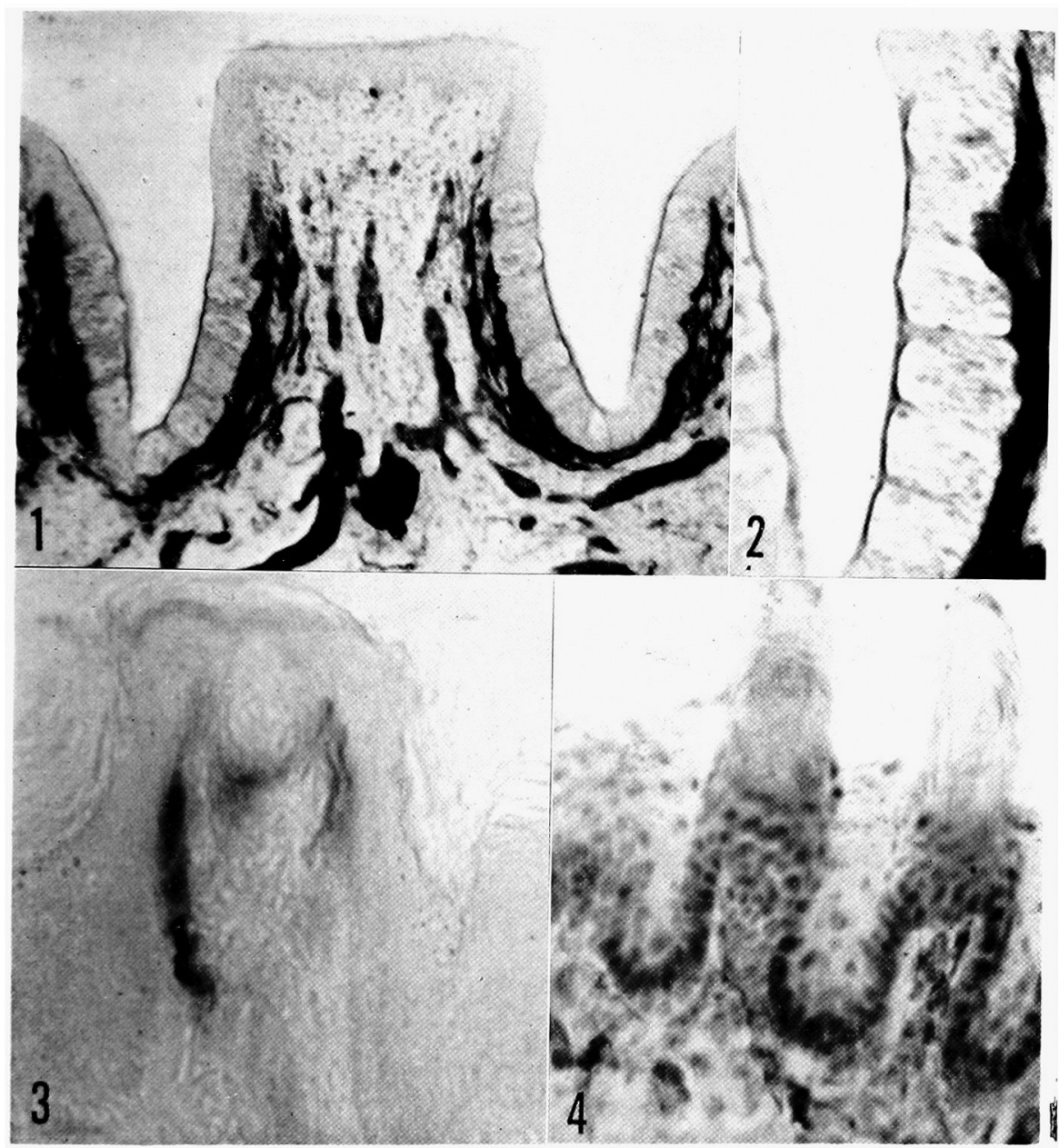

Fig. 1. A vertical section of a vallate papilla of the rat tongue. The rich nerve plexus underlying taste buds along the gutter wall shows strong cholinesterase activity, giving a U-shape cup appearance. Taste buds themselves are negative in reaction. Another strongly reactive nerve tracts accompanied with ganglion cells enter the papillary core, forming a coarse net work. Acetylthiocholine iodide, 2 hours incubation after 1.5 hours fixation, $20 \mu$, counterstained with paracarmine. $\times 100$.

Fig. 2. A portion of the gutter wall of vallate papilla at higher magnification. Note complete absence of cholinesterase reaction in the taste buds in contrast with strong reaction in the nerve plexus underlying them. Acetylthiocholine iodide, 2 hours incubation after 1.5 hours fixation, $20 \mu$, counterstained with paracarmine. $\times 220$.

Fig. 3. A section of a fungiform papilla. Cholinesterase reactions are positive in some nerve fibers entering the papillary core and also around the base of a taste bud at the top of the papilla. Acetylthiocholine iodide, 5 hours incubation after 2 hours fixation, $40 \mu$, no counterstaining. $>300$.

Fig. 4. A section of two filiform papillae. Delicate nerve fibers reactive for cholinesterase enter the core of each papilla. Acetylthiocholine iodide, 4 hours incubation after 30 minutes fixation, $30 \mu$, counterstained with hematoxylin. $>250$. 


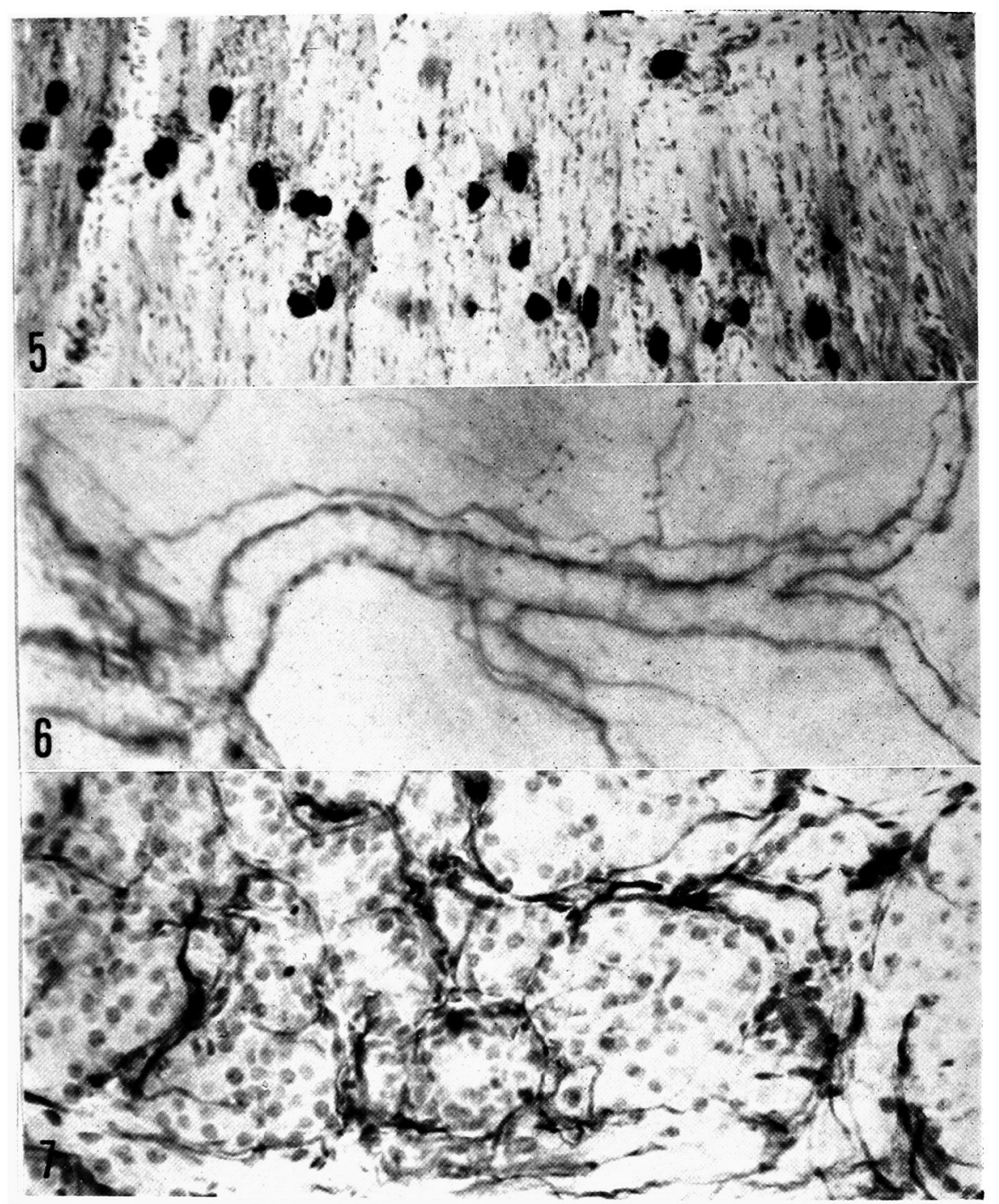

Fig. 5. A portion of the lingual muscle tissue, showing strong cholinesterase reaction at endplates. Butyrylthiocholine iodide, 5 hours incubation after 15 minutes fixation, $30 \mu$, counterstained with paracarmine. 140 .

Fig. 6. A photomicrograph showing cholinesterase-positive nerve fibers which innervate a branching arteriole in the lingual muscle. Acetylthiocholine iodide, 4 hours incubation after 2 hours fixation, $40 \mu$, no counterstaining. $\times 330$.

Fig. 7. A portion of the Ebner's gland. The glandular acini are surrounded with nerve fibers reactive for cholinesterase. Acetylthiocholine iodide, 4 hours incubation after 2 hours fixation, $30 \mu$. counterstained with paracarmine. $\times 330$. 
As shown in Table 1, the reactions with both acetylthiocholine and butyrylthiocholine in the nerve plexus underlying the taste buds in the vallate papilla were found to be completely inhibited by $10^{-4} \mathrm{M}$ eserine, strongly or almost completely by $10^{-5} \mathrm{M}$ and slightly but definitely by $10^{-6} \mathrm{M}$. Eserine in $10^{-7} \mathrm{M}$ exerted almost no inhibitory effect. Similar results were obtained for the fungiform papillae and also for all other reactive sites in the papillary area.

From these results it seems almost unquestionable that the staining reactions with thiocholine substrates in the gustatory region of the rat tongue are actually due to the cholinesterase activity but not to the non-specific esterases.

TABLE 1. The effects of cholinesterase inhibitors on the reactions with thiocholine substrates in the vallate papilla

\begin{tabular}{|c|c|c|c|c|c|c|c|c|}
\hline \multirow{2}{*}{ Inhibitor } & \multirow{2}{*}{ Substrate } & \multicolumn{7}{|c|}{ Molar concentration of inhibitors } \\
\hline & & $10^{-3}$ & $10^{-4}$ & $10^{-5}$ & $10^{-8}$ & $10^{-7}$ & $10^{-8}$ & $10^{-8}$ \\
\hline Eserine & $\begin{array}{l}\text { AThCh } \\
\text { BThCh }\end{array}$ & & $\begin{array}{l}\text { \# } \\
\text { H }\end{array}$ & $\begin{array}{l}H \\
H\end{array}$ & $\begin{array}{l}+ \\
+\end{array}$ & - & & \\
\hline DFP & $\begin{array}{l}\text { AThCh } \\
\text { BThCh }\end{array}$ & & & HH & $\begin{array}{l}\text { \# } \\
\text { \# }\end{array}$ & $\begin{array}{l}+ \\
+1+\end{array}$ & $\begin{array}{l}+ \\
H\end{array}$ & $\overline{+}$ \\
\hline iso-OMPA & $\begin{array}{l}\text { AThCh } \\
\text { BThCh }\end{array}$ & H & $\begin{array}{l}H \\
H\end{array}$ & $\begin{array}{l}H \\
H\end{array}$ & + & $\begin{array}{l}+ \\
H\end{array}$ & $\bar{t}$ & - \\
\hline $\begin{array}{l}\text { AThCh: Ac } \\
\text { H Complet } \\
+ \text { Slight in }\end{array}$ & $\begin{array}{l}\text { ylthiocholi } \\
\text { inhibition } \\
\text { aibition }\end{array}$ & iodic & & $\begin{array}{l}\text { BThCh } \\
\text { H Str } \\
-\quad \text { No }\end{array}$ & $\begin{array}{l}\text { But } \\
\text { ong in } \\
\text { inhib }\end{array}$ & $\begin{array}{l}\text { rylthi } \\
\text { hibiti } \\
\text { ition }\end{array}$ & ocholin & e iodid \\
\hline
\end{tabular}

Effects of DFP and iso-OMPA. As described above, the reactions in the vicinity of the taste buds were positive not only with acetylthiocholine but also with butyrylthiocholine, and the former always gave stronger reaction than the latter. This may indicate that the nerve fibers innervating the taste buds contain both true- and pseudo-cholinesterase, the former being predominant.

In order to discriminate more precisely between the both types of cholinesterase, the effects of DFP and iso-OMPA, both of which are regarded as good selective inhibitors for pseudo-cholinesterase, were examined. Since these inhibitors are of irreversible type, they were applied to the sections prior to the incubation with the substrates. The solutions of these inbibitors in graded molar concentrations were prepared with saturated sodium sulfate solution, and the sections were placed in them for about 30 minutes at $37^{\circ} \mathrm{C}$. Control sections were similarly treated with saturated solution of sodium sulfate without inhibitors for the same period of time. Following such pretreatment, the sections were transferred to the incubation solution containing acetylthiocholine or butyrylthiocholine.

The results are summarized in Table 1. The reaction with butyrylthiocholine in the vicinity of taste buds was found to be totally abolished by DFP and isoOMPA in concentrations as low as $10^{-7} \mathrm{M}$ and $10^{-6} \mathrm{M}$, respectively. Furthermore, 
partial inhibition was obtained with DFP up to the concentration as low as $10^{-9} \mathrm{M}$ and with iso-OMPA up to $10^{-8} \mathrm{M}$.

When acetylthiocholine was used as substrate, the higher concentrations were needed to obtain complete inhibition of the staining; that is, $10^{-5} \mathrm{M}$ for DFP and $10^{-3} \mathrm{M}$ for iso-OMPA. However incomplete suppression of the reaction with acetylthiocholine was produced by DFP in $10^{-6}$ to $10^{-8} \mathrm{M}$ and by iso-OMPA in $10^{-4}$ to $10^{-7} \mathrm{M}$.

\section{Effects of Bitter Substances on the Cholinesterase Activities in the Taste Bud Areas}

As the materials for this experiment, only the sections of the area of vallate papilla were used, attention being paid to the taste bud areas.

Following substances with bitter taste were selected for the present study: quinine hydrochloride, methantheline bromide, berberine hydrochloride, Lmethylephedrine hydrochloride, phenobarbital sodium, sodium dehydrocholate and phenylthiocarbamide. As control experiments, some sweet-tasting substances such as sucrose, sodium cyclohexylsulfamate and saccharin sodium were also tested for the effect on the cholinesterase activities.

Effect on the true-cholinesterase. In order to test the effect on the truecholinesterase selectively, the pseudo-cholinesterase was previously eliminated by pretreatment with iso-OMPA. That is, the sections were placed for 30 minutes in the saturated sodium sulfate solution containing iso-OMPA at a concentration of $10^{-6} \mathrm{M}$, which was determined to be effective in producing complete inhibition of pseudo-cholinesterase with slight interference with true-cholinesterase (Table 1), and then they were incubated with acetylthiocholine solution, to which the taste substances were previously added in graded molar concentrations. The control sections were incubated with acetylthiocholine solution without taste substances.

As indicated in Table 2, all of the bitter substances tested were found to exhibit more or less inhibitory effects on the true-cholinesterase activity, except that only phenylthiocarbamide failed to produce definite inhibition up to $10^{-3} \mathrm{M}$, which was nearly the maximal limit of this substance for solubility in the incubation solution.

The most effective one among these was berberine hydrochloride. It caused an inhibition, though slight, at concentrations as low as $10^{-6}$ to $10^{-7} \mathrm{M}$, and strong inhibition at $10^{-5} \mathrm{M}$. Methantheline bromide and quinine hydrochloride were effective in producing slight inhibition up to $10^{-5} \mathrm{M}$, and L-methylephedrine hydrochloride and sodium dehydrocholate up to $10^{-4} \mathrm{M}$. Phenobarbital sodium was the least effective, giving slight inhibition at $10^{-2} \mathrm{M}$ at most.

In contrast to these bitter substances, all of the sweet-tasting substances tested failed to show any inhibitory effect on the true-cholinesterase at concentrations of $10^{-4}$ to $10^{-2} \mathrm{M}$. 
TABLE 2. The effects of taste-provoking substances on the true-cholinesterase activity in the vicinity of the taste buds in the vallate papilla

\begin{tabular}{|c|c|c|c|c|c|c|c|}
\hline & \multicolumn{7}{|c|}{ Molar concentrations } \\
\hline & $10^{-2}$ & $10^{-3}$ & $10^{-4}$ & $10^{-5}$ & $10^{-6}$ & $10^{-7}$ & $10^{-8}$ \\
\hline Quinine hydrochloride & & $H$ & + & + & - & - & \\
\hline Methantheline bromide & H & $H$ & + & + & - & & \\
\hline Berberine hydrochloride & & & $H^{*}$ & $H$ & + & + & - \\
\hline $\begin{array}{l}\text { L-Methylephedrine } \\
\text { hydrochloride }\end{array}$ & H & + & + & - & & & \\
\hline Phenobarbital sodium & + & - & - & & & & \\
\hline Sodium dehydrocholate & H & H & + & - & & & \\
\hline Phenylthiocarbamide & & - & - & - & - & & \\
\hline Sucrose & - & - & & & & & \\
\hline $\begin{array}{l}\text { Sodium } \\
\text { cyclohexylsulfamate }\end{array}$ & - & - & - & & & & \\
\hline Saccharin sodium & - & - & - & & & & \\
\hline $\begin{array}{l}\text { H Com } \\
+\quad \text { Sligh }\end{array}$ & $\begin{array}{l}\text { te inh } \\
\text { nhibit }\end{array}$ & $\begin{array}{l}\text { bition } \\
\text { on }\end{array}$ & & $\begin{array}{l}H \\
-\end{array}$ & $\begin{array}{l}\text { rong } i \\
\text { o inhil }\end{array}$ & $\begin{array}{l}\text { nhibit } \\
\text { ition }\end{array}$ & \\
\hline
\end{tabular}

TABLE 3. The effects of taste-provoking substances on the pseudo-cholinesterase activity in the vicinity of the taste buds in the vallate papilla

\begin{tabular}{|c|c|c|c|c|c|c|c|}
\hline & \multicolumn{7}{|c|}{ Molar concentrations } \\
\hline & $10^{-2}$ & $10^{-3}$ & $10^{-4}$ & $10^{-5}$ & $10^{-6}$ & $10^{-7}$ & $10^{-8}$ \\
\hline Quinine hydrochloride & & H & + & - & & & \\
\hline Methantheline bromide & \# & H & H & $H$ & + & - & \\
\hline Berberine hydrochloride & & & $+*$ & - & - & & \\
\hline $\begin{array}{l}\text { L-Methylephedrine } \\
\text { hydrochloride }\end{array}$ & t & + & - & & & & \\
\hline Phenobarbital sodium & + & - & - & & & & \\
\hline Sodium dehydrocholate & H & + & - & & & & \\
\hline Phenylthiocarbamide & & - & - & - & - & & \\
\hline Sucrose & - & - & & & & & \\
\hline $\begin{array}{l}\text { Sodium } \\
\quad \text { cyclohexylsulfamate }\end{array}$ & - & - & - & & & & \\
\hline Saccharin sodium & - & - & - & & & 1 & \\
\hline $\begin{array}{ll}+ \text { H } & \text { Com } \\
+ & \text { Sligh }\end{array}$ & $\begin{array}{l}\text { te inh } \\
\text { nhibit }\end{array}$ & lbition & & + & $\begin{array}{l}\text { trong } \\
\text { o inhi }\end{array}$ & $\begin{array}{l}\text { inhibit } \\
\text { bition }\end{array}$ & \\
\hline
\end{tabular}

Effect on the pseudo-cholinesterase. In the test for pseudo-cholinesterase, the sections, without any pretreatment, were incubated with butyrylthiocholine solution in which the test substances were mixed in graded molar concentrations, the sections incubated with the substrate alone being served as control.

All of the bitter substances, except phenylthiocarbamide, were also found to be good inhibitors for pseudo-cholinesterase (Table 3). Their effects were gener- 
ally less remarkable as compared with those on the true-cholinesterase, though their relative potencies of inhibition were not always parallel to those for true-cholinesterase.

The most significant difference occurred with berberine hydrochloride. This substance, which was the most potent inhibitor for true-cholinesterase, failed to inhibit pseudo-cholinesterase up to a concentration of $10^{-5} \mathrm{M} ; 5 \times 10^{-5} \mathrm{M}$, a critical level for solubility, gave at most a slight reduction of the reaction with butyrylthiocholine. Methantheline bromide exceptionally showed inhibitory effect on the pseudo-cholinesterase 10 times stronger than to true-cholinesterase, and this substance was found to be the most potent inhibitor for pseudo-cholinesterase.

All of the sweet substances tested were found to be free of any inhibitory action on the reaction with butyrylthiocholine.

\section{Discussion}

The present investigation has shown that in the rat tongue cholinesterases of both true and pseudo types are abundantly present in the nerve fibers innervating the taste buds in the vallate and fungiform papillae. This finding is in agreement with that in other mammals ${ }^{4,5}$ and in man.6,7 However the taste buds themselves in the rat were almost free of cholinesterase reaction, in spite of the strong reaction in the taste nerve plexus underlying them. This is in contrast to the finding in the tongue of the rabbit, in which cholinesterase was clearly shown to be contained in the taste buds in association with the intragemmal nerve fibers, especially in the basal portion of the taste buds. ${ }^{4,5}$ Similar results were also reported on the tongue in some primates ${ }^{5}$ and in man,,$^{6,7}$ but without showing clear-cut intragemmal localization such as found in the rabbit tongue., ${ }^{4,5}$ In the present observation unfixed thick sections, particularly with longer time of incubation, often showed some diffuse staining at the base of the taste buds, but it was difficult to relate it with any of the intragemmal elements. It seems quite likely that such a diffuse staining reaction may result from a diffusion artifact from the strongly reactive nerve plexus immediately underneath the taste buds, though the possibility cannot be entirely ruled out that the intragemmal nerve fibers in the rat tongue might contain some cholinesterase. The present work also showed the absence of perigemmal or intergemmal nerve fibers reactive for cholinesterase in the rat tongue, which forms another prominent contrast to the rabbit tongue. ${ }^{4,5}$ Apart from these respects described above, the overall picture of the cholinesterase localizations in the tongue of the rat was found to be essentially comparable to that in other mammals ${ }^{4,5}$ as well as in man. ${ }^{6,7}$

The fact that the taste buds are richly supplied with nerve fibers which contain abundant cholinesterase may suggest that a cholinergic mechanism is involved in the initiation of nervous impulse at the taste receptor. Evidence in support of this assumption was obtained by Landgren et al. ${ }^{20}$ They reported 
that in the frog tongue the action potential in the lingual branch of the glossopharyngeal nerve, which was produced spontaneously as well as by some taste stimuli, was enhanced by anticholinesterases and was reduced by acetylcholineantagonizers such as tubocurarine and decamethonium applied to the surface of the tongue. Recently, however, such concept was disputed by Duncan, ${ }^{21}$ who obtained contradictory results that the gustatory sensitivity in the frog tongue failed to be affected not only by cholinesterase inhibitors but also by tubocurarine, hexamethonium and decamethonium. From these results he denied the cholinergic mechanism at the synapse between the taste bud and its afferent neuron. The actual functional significance of cholinesterase in the taste nerve is still far from being established and requires further investigations.

Baradi and Bourne $\mathrm{e}^{1-3}$ postulate that the variety in the changes of enzyme activities in the gustatory area, which would be produced by a number of taste substances, may be associated with the initiation of various kinds of taste sensations, and that if the substances of different chemical natures affect some of the gustatory enzymes in a similar manner, all of these substances would be perceptible as the same taste. In the present research it was confirmed that several kinds of bitter substances, which are different in their chemical natures and structures, have a common property to inhibit the cholinesterase activity in the vicinity of taste buds. In contrast, all of the sweet substances tested were found to be devoid of such ability. These findings may favor the concept proposed by Baradi and Bourne $\mathrm{e}^{-3}$ and provide a suggestion, though rather speculative, that the deviation of the cholinesterase activity in the taste nerve terminals might play a role in the perception of bitter taste. The present data, however, are too limited and a definite conclusion should await further investigations. In this connection, it may be added that one of us $(\mathrm{T})$ found recently that the strength of bitterness of above substances on the human tongue, which was roughly estimated by their taste threshold concentrations, paralleled, though not strictly, their effectiveness of cholinesterase inhibition. The details of the results will be given in a separate paper.

It is of interest to note that among the bitter substances tested in the present experiments, only phenylthiocarbamide failed to exert inhibitory effect on the cholinesterase. Phenylthiocarbamide and allied substances are known to have a peculiar property that they taste extremely bitter for the most persons but are tasteless to some persons. ${ }^{22,23}$ Such phenomenon was first described by Fox, ${ }^{22}$ who designated it as 'taste blindness'. It may be presumed that the mechanism of provoking bitter taste sensation of phenylthiocarbamide and its derivatives differs from that of other bitter substances.

\section{Acknowledgment}

We are indebted to Prof. S. Okui and Asst. Prof. M. Uchiyama for their constant advice and encouragement throughout this work. 
Our thanks are also due to L. Light \& Co. Ltd. for the supply of iso-OMPA, to Merck \&

Co. Inc. for DFP and to Hoffman-La Roche Inc. for butyrylthiocholine iodide.

\section{References}

1) Baradi, A.F. \& Bourne, G.H. Localization of gustatory and olfactory enzymes in the rabbit, and the problems of taste and smell. Nature (Lond.), 1951, 168, 977979.

2) Baradi, A.F. \& Bourne, G.H. Theory of tastes and odors. Science, 1951, 113, 660661 .

3) Baradi, A.F. \& Bourne, G.H. Gustatory and olfactory epithelia. Int. Rev. Cytol., 1953, 2, 289-330.

4) Baradi, A.F. \& Bourne, G.H. Histochemical localization of cholinesterase in gustatory and olfactory epithelia. J. Histochem. Cytochem., 1959, 7, 2-7.

5) Ellis, R.A. Cholinesterase in the mammalian tongue. J. Histochem. Cytochem., 1959, 7, $156-163$.

6) Rakhawy, M.T.El. \& Bourne, G.H. Cholinesterases in the human tongue. Bibl. anat. (Basel), 1960, 2, 243-255.

7) Rakhawy, M.T. El. \& Bourne, G.H. The histochemistry of the human foetal tongue. Acta anat., 1964, 56, 93-102.

8) Wedell, C.H. The taste sensitivity of the white rat. J.comp. Psychol., 1936, 21, 233-244.

9) Richter, C.P. Salt taste thresholds of normal and adrenalectomized rats. Endocrinology, 1939, 24, 367-371.

10) Richter, C.P. \& MacLean, A. Salt taste threshold of humans. Amer. J. Physiol., $1939,126,1-6$.

11) Richter, C.P. \& Campbell, K.H. Sucrose taste thresholds of rats and humans. Amer. J. Physiol., 1940, 128, 291-297.

12) Richter, C.P. \& Clisby, K.H. Phenylthiocarbamide taste thresholds of rat and human beings. Amer. J. Physiol., 1941, 134, 157-164.

13) Gomori, G. Microscopic Histochemistry: Principles and Practice. Univ. of Chicago Press, Chicago, 1952, pp. 210-212.

14) Koelle, G.B. \& Friedenwald, J.S. A histochemical method for localizing cholinesterase activity. Proc. Soc. exp. Biol. Med. (N.Y.), 1949, 70, 617-622.

15) Koelle, G.B. The elimination of enzymatic diffusion artifacts in the histochemical localization of cholinesterases and a survey of their cellular distributions. $J$. Pharmacol. exp. Ther., 1951, 103, 153-171.

16) Oppel, A. Lehrbuch der vergleichenden microskopischen Anatomie der Wirbeltiere. III. Gustar Fischer, Jena, 1900, pp. 357-361.

17) Tuckerman, F. Further observations on the gustatory organs of the mammalia. J. Morphol., 1892, 7, 69-94.

18) Lovén, C. Beiträge zur Kenntniss vom Bau der Geschmackswärzchen der Zunge. Arch. mikr. Anat., 1868, 4, 96-109.

19) Oppel, A. The same as (16), pp. 358, 454, 469.

20) Landgren, S., Liljestrand, G. \& Zotterman, Y. Chemical transmission in taste fibre endings. Acta physiol. scand., 1954, 30, 105-114.

21) Duncan, C.J. Synaptic transmission at taste buds. Nature (Lond.), 1964, 203, 875-876.

22) Fox, A.L. The relationship between chemical constitution and taste. Proc. nat. Acad. Sci. USA, 1932, 18, 115-120.

23) Hopkins, C.Y. Taste differences in compounds having the NCS linkage. Canad. J. Research, 1942, 20-B, 268-273. 